\title{
AN INNOVATIVE JIG TO TEST MECHANICAL BEARINGS EXPOSED TO HIGH VOLTAGE ELECTRICAL CURRENT DISCHARGES
}

Nicolaas Steenekamp

Gauteng Department of Infrastructure Development, Impophoma House,

Johannesburg, (South Africa).

E-mail: nicolaas.steenekamp@gauteng.gov.za ORCID: http://orcid.org/0000-0001-6858-4207

Arthur James Swart

Department of Electrical, Electronic and Computer Engineering, Central University of Technology,

Bloemfontein, (South Africa).

E-mail: aswart@cut.ac.za ORCID: http://orcid.org/0000-0001-5906-2896

\section{Gitación sugerida Suggested citation}

Steenekamp, N., y Swart, A. J. (2020). An innovative jig to test mechanical bearings exposed to high voltage electrical current discharges. 3C Tecnología. Glosas de innovación aplicadas a la pyme. Edición Especial, Abril 2020, 195-215. http://doi.org/10.17993/3ctecno.2020.specialissue5.195-215 


\section{ABSTRACT}

Premature bearing failures due to Electrical Current Discharge (ECD) has been recognised for almost a century. The purpose of this paper is to present an innovative jig that may be used to expose mechanical bearings to ECD, in order to clarify its associated effects on the bearing that need to be understood before any mitigating techniques can be proposed. An experimental design is used in this study. A method is presented using an ignition coil wiring harness of a vehicle to safely induce ECD across a specific bearing. Three samples were used and analysed with an optical and electron scanning microscope. The used ball bearing exposed to ECD showed micro-cratering, a result of electric current passage. Micro arching marks on the raceway surface of this bearing was also visible, and especially near the groove of the synthetic rubber seal and steel plate slinger. Surface pits were observed which were produced by electrical arching. A few deep scratches and indentations were observed on the raceway surface. This is due to abrasive wear particles embedded in the raceway surface sliding between the major bearing components. The aspect of electrical pitting wear and debris found in the lubricating oil are unknown and deserve further research from a tribological point of view. A recommendation is made to use this innovative jig to test the impact of ECD on bearings from other suppliers.

\section{KEYWORDS}

Electrical Current Discharges, Micro Arching, Micro Cratering, Ball Bearing, LOM, SEM. 


\section{INTRODUCTION}

The global bearings market was valued at approximately USD 92.81 billion in 2017 (Bizwit Research \& Consulting LLP, 2019). Ball bearings are a common component in machinery that finds widespread use in numerous industrial applications. These include air, water and land transport, agriculture, construction, manufacturing and mining industries. Premature bearing failures is one of the main reasons for machinery down time (Jacobs et al., 2016). The failure mechanisms of bearings have been well researched and documented i.e. Brinelling, Contamination, Corrosion, Fatigue, Fit, Lubrication, Misalignment and Overloading (Massi et al., 2010; Bhadeshia, 2012; Upadhyay, Kumaraswamidhas, \& Azam, 2013).

However, bearings may also fail due to Electrical Current Discharges (ECD) that may originate with lightning, high voltage spikes or high potential differences. The cause of bearing failure due to electric current passage has been recognised for almost a century (Liu, 2014). As a matter of fact, electric potential difference exists between shafts and bearing housings in machinery equipment due to the asymmetric effects of the magnetic fields, magnetized shaft, and electrostatic effects, etc. (Chiou, Lee, \& Lin, 2009). Some practical solutions to mitigate bearing currents has worked effectively for sinusoidal alternating currents i.e. shaft grounding to bypass current, ceramic-coated bearings and hybrid insulated bearings. Some of these solutions are not as effective against the fast switching Pulse Width Modulation (PWM) inverter technology that causes high frequency non-sinusoidal bearing current (Liu, 2014). A diversity of condition monitoring techniques exist that can be used to identify developmental bearing failure.

The purpose of this paper is to present an innovative jig that may be used to expose mechanical bearings to ECD, in order to clarify its associated effects on the bearing that need to be understood before any mitigating techniques can be proposed. Firstly, an overview of the construction and operation of different types of key bearings is presented. Secondly, analysis techniques are presented to separate a single failure mechanism from the complex mechanisms. Thirdly, a method is presented using an ignition coil wiring harness of a vehicle to safely induce ECD across a specific bearing. Fourthly, the obtained results are discussed. Finally, concluding remarks and recommendations are presented. 


\section{MAIN BEARING CLASSIFICATIONS}

An organogram outlining the classification of commonly found bearings is as shown Figure 1 (NTN Corporation, 2015). A rolling bearing consists of four major components: an inner and outer raceway, rolling elements and a cage that maintains equally spaced intervals between the rolling elements. The rolling elements are situated between the inner and outer raceways to translate motion. Rolling bearings are grouped into two main rolling element classifications, ball bearings and roller bearings. Ball bearings are classified by the raceway type: deep groove or angular contact. Roller bearings are classified by the roller type: cylindrical, needle, tapered, and spherical (NTN Corporation, 2015). Roller bearings typically have greater load carrying capacities because of the greater contact area of the roller bearings to the adjacent raceway surfaces (Bhadeshia, n.d.).

Furthermore, rolling bearings can also be classified by the load type: radial or thrust. Radial bearings support radial loads and thrust bearings support axial loads. Most roller bearings can simultaneously support radial and thrust loads (NTN Corporation, 2015). Rolling bearings are also supplied in multiples of separable and non-separable rolling rows, for example single, double and quadruplet configurations. The choice of a bearing and configuration depends on the stiffness and load requirements of the application. A brief discussion on some of these bearings now follows.

Duplex angular contact ball bearings are typically selected to increase stiffness and load carrying capacity of the support ends of upright and overhung shafts and screw drives (SKF Group, n.d.a). Angular contact ball bearings have inner and outer ring raceways that are displaced relative to each other in the direction of the bearing axis. The configurations are typically back-to-back, face-to-face and tandem. Duplex angular contact ball bearings are most commonly found in centrifugal pumps (SKF Group, 2012a).

Self-aligning ball bearings are typically selected for industrial applications where low friction is preferred over high load carrying capacity to accommodate misalignment, shaft deflections and thermal expansion (SKF Group, n.d.b). Furthermore, the self-aligning ball bearing has the lowest friction of all rolling bearings which allows them to operate at higher speeds and cooler temperatures (SKF Group, 2018). Self-aligning ball bearings have two raceways on the inner ring and has a single spherical raceway on the outer ring that can 
counteract up to three degrees of misalignment. Tapered bore ball bearings induce bearing preload and are typically secured with adapter sleeves to smooth or stepped shafts. They are typically found in paper mills (SKF Group, 2018) and the textile industry (SKF Group, 2014).

Like duplex angular contact ball bearings, high-speed duplex angular contact ball bearings are typically selected for applications that demand high reliability and superior accuracy, for example a machine tool spindle in CNC turning, machining centre and milling machine (SKF Group, 2012b). High-speed duplex bearings are usually sealed to eliminate contamination to prevent premature bearing failures.

Radial needle roller bearings are typically selected for their stiffness and high load carrying capacity (SKF Group, n.d.c). The diameter of a roller element of a needle roller bearing is relatively small in relation to its length. Needle roller bearings are used in applications where space is limited. Typically, a needle roller is combined with a shaft or housing bore to serve as a raceway. They are used, for example, in the universal joint of a drive shaft and rocker-arm pivot of a vehicle (SKF Group, n.d.d).

Spherical thrust roller bearings are well suited for heavy-duty applications where axial and or combined axial and radial loads needs to be accommodated (SKF Group, 2010). Spherical thrust roller bearings are like self-aligning ball bearings and are typically found in a cooling water pump for a thermal power plant and marine thrusters ("SKF explorer spherical roller thrust bearings boost design options", 2003). 


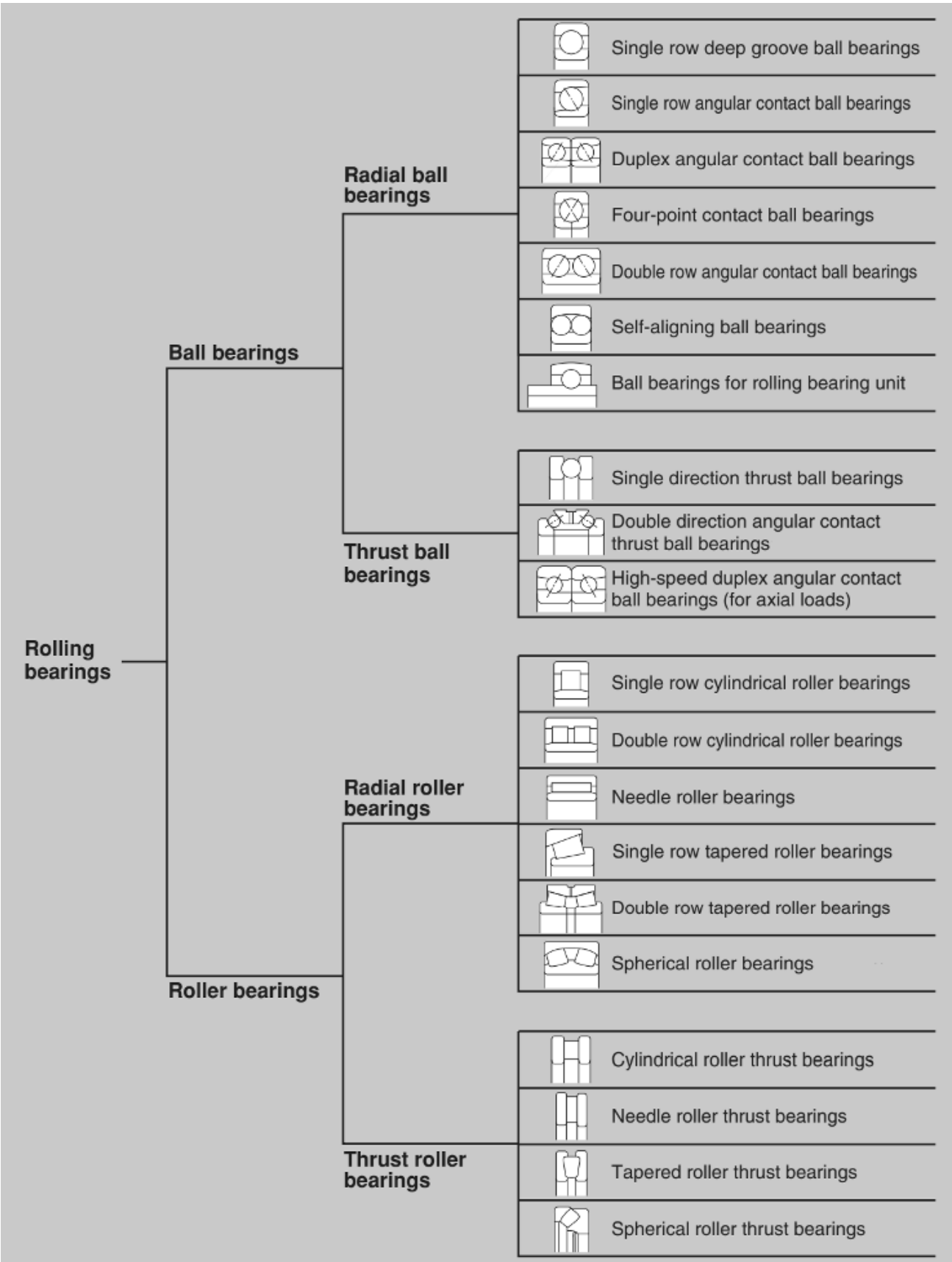

Figure 1. Classification of rolling bearings. Source: (NTN Corporation, 2015).

For this research work, a radial ball bearing for rolling bearing units, as shown in Figure 2 , is selected as it is cost effective and has a basic mounting interface that can be used 
between the surface of the jig and the pulley shaft system. This type of bearing is based on a sealed deep groove ball bearing. The ring of the outer raceway is convex to allow for shaft miss-alignment by tilting in the rolling bearing unit, and the ring of the inner raceway is extended with a locking device to enabling quick and easy mounting onto shafts (SKF Group, n.d.e). The structural diagram of the radial ball bearing for rolling bearing unit used is shown in Figure 3.

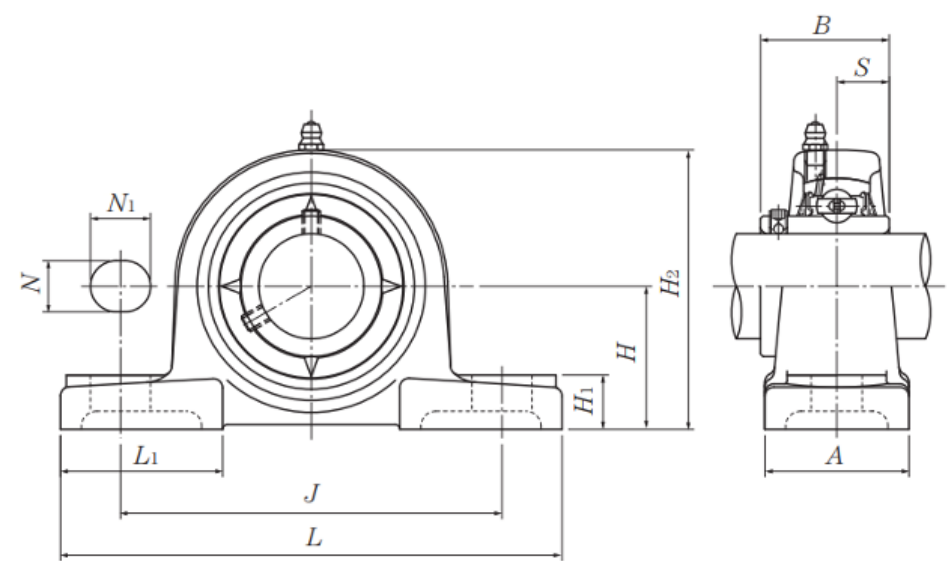

\begin{tabular}{|c|c|c|c|c|c|c|c|c|c|c|c|c|c|c|}
\hline \multirow{3}{*}{$\begin{array}{c}\text { Shaft } \\
\text { dia. }\end{array}$} & \multirow[t]{3}{*}{ Unit number } & \multicolumn{11}{|c|}{ Nominal dimensions } & \multirow{3}{*}{$\begin{array}{l}\text { Bolt } \\
\text { size }\end{array}$} & \multirow[t]{3}{*}{ Bearing number } \\
\hline & & \multicolumn{11}{|c|}{$\mathrm{mm}$} & & \\
\hline & & $H$ & $L$ & $J$ & $A$ & $N$ & $N_{1}$ & $H_{1}$ & $H_{2}$ & $L_{1}$ & $B$ & $s$ & & \\
\hline 20 & UCP204D1 & 33.3 & 127 & 95 & 38 & 13 & 16 & 14 & 65 & 42 & 31 & 12.7 & M10 & UC204D1 \\
\hline
\end{tabular}

Figure 2. Radial ball bearing for rolling bearing unit. Source: (NTN Corporation, 2018).

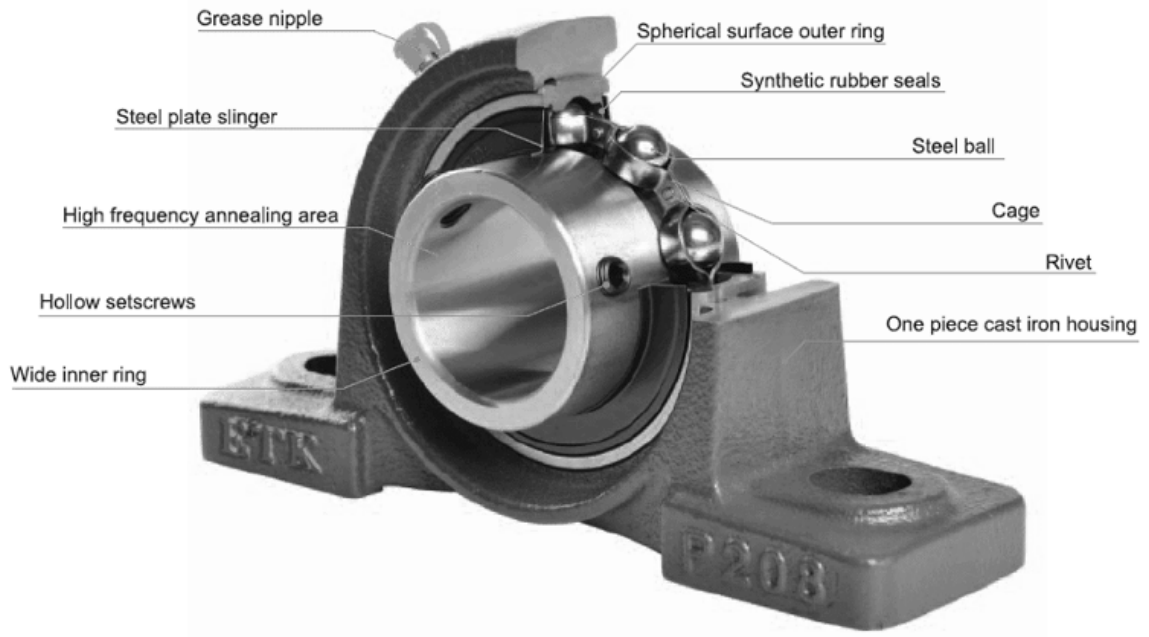

Figure 3. Structural diagram of the radial ball bearing for rolling bearing unit. Source: (ETK Bearing Company, n.d.). 
Rolling bearings for special applications such as journal bearings, linear actuators, and linear motion products are excluded from the scope of this work, as the main objective is to initially verify the operation of the jig along with its results. Various techniques exist to analyse these bearings for damage after they have been used, as discussed in the next subsection.

\section{BEARING ANALYSIS TECHNIQUES}

Various techniques exist to analyse bearings after they have been damaged by ECD. Typical evaluations include Solid particle analysis, Fourier Transform Infrared Spectroscopy (FTIR), Light optical microscope (LOM), Scanning Electron Microscope (SEM) and Chemical Analysis.

Solid particle analysis is an excellent technique to analyse debris found in the lubrication of machinery. The morphological results of the wear debris of the components are key in determining commonalities. A particle separating disk is used to separate the solid debris particles from the lubrication for viewing under a microscope. Adequate magnification and lighting are required for viewing and analysis of the filter patches (Raadnui, 2012).

FTIR is used to examine the degradation of lubrication (Aditya, Amarnath, \& Kankar, 2014). The FTIR analyser is used to record the transmittance spectrum of new and used lubrication. The Nitration Index and Oxidation Index are widely applied for quantifying the oil degradation in used oil analysis. Nitration products have a characteristic absorbance between the wavenumber range of $1650 \mathrm{~cm}^{-1}$ and $1600 \mathrm{~cm}^{-1}$, the region immediately below that of the oxidation products. Oil oxidation occurs in the carbonyl $(\mathrm{C}=\mathrm{O})$ region between the wavenumber range of $1800 \mathrm{~cm}^{-1}$ and $1670 \mathrm{~cm}^{-1}$ (Robinson, n.d.).

LOM analysis is popular as it illuminates and magnifies small samples that are difficult to clearly observe with the naked eye. Purely digital microscopes are now available that directly display images on a computer screen (Gianfrancesco, 2017). One of the disadvantages of LOM is the relatively large resolution limit. The resolution limit is controlled by diffraction, which in turn is controlled by the numerical aperture of the optical system and the wavelength of the light used. Another disadvantage of LOM is the poor contrast produced when light is reflected off surfaces with a high degree of reflectivity (Bergström, 2015). 
The SEM overcomes these challenges. The magnification power of the electron microscope is continually improving, with modern field emission scanning electron microscopy (FESEM) providing magnifications of up to 550000 times and resolutions down to $0.5 \mathrm{~nm}$ (Ingham, 2013). SEM instrumentation is equipped with energy dispersive spectroscopy (EDS) system that allows for the study of the topography, morphology, chemical composition and crystallographic Information (Scimeca et al., 2018). The techniques as shown in Table 1 will be applied to the used samples bearings to analyse ECD damage.

Table 1. Bearing analysis techniques.

\begin{tabular}{|c|c|c|c|}
\hline No & $\begin{array}{c}\text { Analysis } \\
\text { technique }\end{array}$ & Equipment model number & Purpose of analysis technique \\
\hline 1 & LOM analysis & Celestron 44302 & LOM will provide initial images of any damage \\
\hline 2 & $\begin{array}{c}\text { SEM/EDS } \\
\text { analysis }\end{array}$ & Jeol JSM 6610 & SEM will verify the images and provide chemical \\
composition
\end{tabular}

\section{THE INNOVATIVE JIG}

This section presents the innovative jig that may be used to expose mechanical bearings to ECD and is shown in Figure 4. The labels are presented in Table 2 with a short description and purpose.

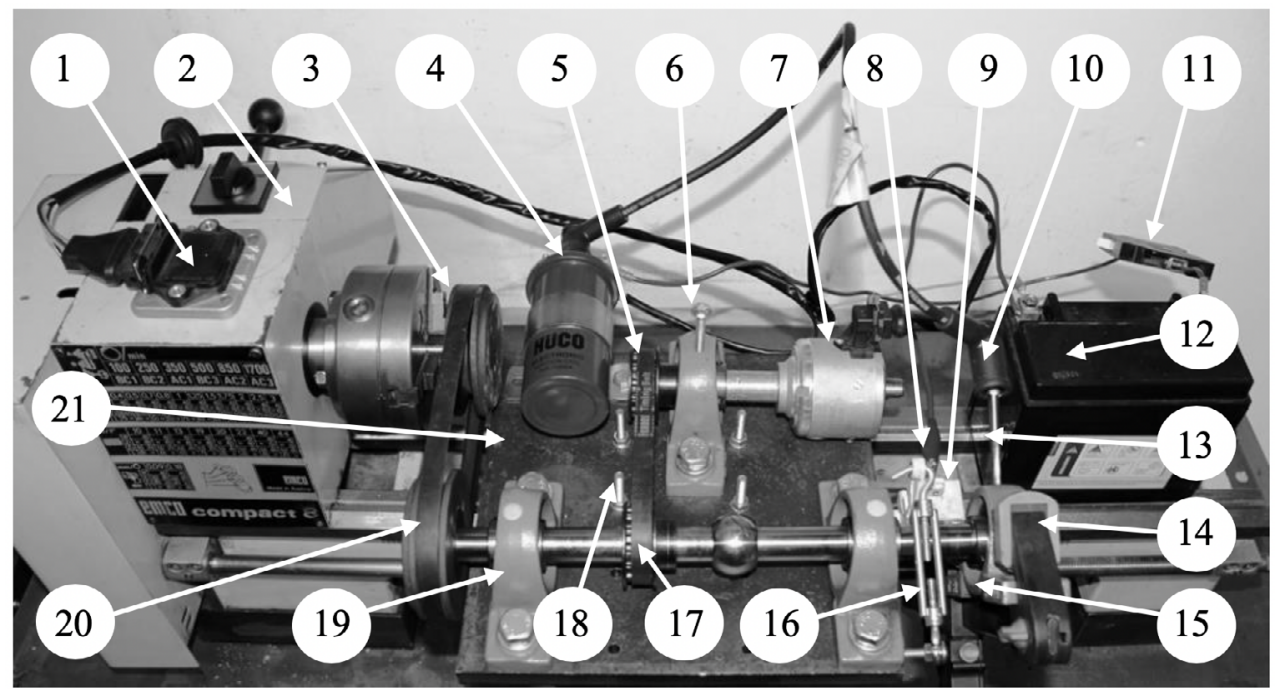

Figure 4. The innovative jig.

The innovative jig comprises readily available components in South Africa. Some of the components required minimal alterations to fit into the jig, without compromising its 
functionality. The separation of the carbon brush holder from the voltage regulator of an automotive alternator was challenging due to the poor stiffness of the material and to perform workpiece clamping of the carbon brush holder. A variety of prying tools were successfully used to separate the carbon brush holder from the voltage regulator.

Another challenge encountered was in reducing the shank circumference of the ignition distributor to fit through the wide inner ring of the rolling bearing unit for rigid mounting purposes. The internal cavity of the ignition distributor seems to have been pre-cast asymmetrical, causing the tooling to rupture through the thinned wall sections along the shank. The shank circumference at the drive gear end of the ignition distributor has an internal plain bearing which offered enough clamping support for rigid mounting purposes that overcame this challenge. The overall cost of the project was approximately USD 336.

Table 2. List of components of the innovative jig and their purpose.

\begin{tabular}{|c|c|c|c|}
\hline No & Description & Purpose \\
\hline 1 & Ignition control module & Electronic switch to control timing between discharges of the ignition \\
coil
\end{tabular}




\begin{tabular}{|c|c|c|}
\hline No & Description & Purpose \\
\hline 14 & Insulated G-clamp & $\begin{array}{l}\text { Rotational restraint and grounding isolator for the radial ball bearing } \\
\text { sample }\end{array}$ \\
\hline 15 & Radial ball bearing sample & $\begin{array}{l}\text { Radial ball bearing sample fixed to the shaft with two hollow set } \\
\text { screws as shown in Figure } 3\end{array}$ \\
\hline 16 & Turnbuckle hook to eye & $\begin{array}{l}\text { A screw mechanism used to adjust the contact depth of the spring- } \\
\text { loaded carbon brush to the linear shaft }\end{array}$ \\
\hline 17 & Jig Timing belt and pulley & Parallel alignment of timing belt and driving timing pulley \\
\hline 18 & Jig mounting screw & $\begin{array}{l}\text { The jig attaches to the cross slide of the lathe. The V-belt is tensioned } \\
\text { between the lathe end driving pulley and jig end driven pulley }\end{array}$ \\
\hline 19 & Shaft bearing supports & Typical bearing support ends for the shaft to allow rotational motion \\
\hline 20 & Jig V-belt and pulley & Driven pulley output shaft speed, 850 revolutions per minute (rpm) \\
\hline 21 & Base plate of jig & Mounting interface for selected components \\
\hline
\end{tabular}

\section{METHODOLOGY}

This section presents the method to safely induce ECD across a radial ball bearing for rolling bearing units, in order to clarify its associated effects on the bearing that need to be understood before any mitigating techniques can be proposed. An experimental design is used which may be considered as a detailed investigational plan to obtain the maximum amount of information specific to the objectives (McIntosh \& Pontius, 2017). The detailed investigational plan in this study starts with:

- Assembly procedure of the innovative jig as shown in Figure 4 and Table 2;

- The location and weather conditions of the research site as shown in Table 3;

- Test parameters for the radial ball bearing for rolling bearing unit samples as shown in Table 4;

- To cut material samples from each of the tested radial ball bearing for rolling bearing units for LOM and SEM analyses.

Table 3. The location and weather conditions of the research site.

\begin{tabular}{|c|c|c|c|c|c|c|}
\hline Latitude & Longitude & Elevation & Season & Temperature & Wind & Humidity \\
\hline $25^{\circ} 47^{\prime} 34.744^{\prime \prime}$ & $28^{\circ} 19^{\prime} 5.77^{\prime \prime} \mathrm{E}$ & $1418 \mathrm{~m}$ & Spring & $22^{\circ} \mathrm{C}$ & $13 \mathrm{~km} / \mathrm{h}$ & $53 \%$ \\
\hline
\end{tabular}

Table 4. Test parameters for the radial ball bearing for rolling bearing unit samples.

\begin{tabular}{|c|c|c|c|}
\hline Sample & Time & Shaft Speed & ECD \\
\hline 1 & 0 minutes & 0 rpm & No \\
\hline 2 & 15 minutes & $850 \mathrm{rpm}$ & No \\
\hline 3 & 15 minutes & $850 \mathrm{rpm}$ & Yes \\
\hline
\end{tabular}


An ignition coil wiring harness of a vehicle was used to induce ECD across a radial ball bearing. This product was selected because it is widely used in the automotive industry, and readily available over the counter. The test parameters for the radial ball bearing samples are shown in Table 4. The experiment was done on 31 October 2019 at 19h00. Sample 1 was kept unused as new with the purpose of being a control sample with which to compare and evaluate the other two samples. Sample 2 and 3 were both exposed to a shaft rotational speed of $850 \mathrm{rpm}$ for fifteen-minutes.

Only sample 3 was exposed to ECD. Sample 2 and 3 were rigidly mounted with two hollow set screws onto a linear shaft section of the innovative jig, as shown in Figure 4. An insulated G-clamp was mounted on each sample as a rotational restraint and grounding isolator. For sample 3, the cathode terminal was connected to the carbon brush holder. A thread cutting tap was screwed into the grease nipple hole of the bearing unit of sample 3 to create a spark gap of two millimetres between the outer raceway anode terminal. The bench lathe was switched on and brought up to a speed of $850 \mathrm{rpm}$. The power supply circuit breaker was activated, and the fifteen-minute countdown started. Samples were cut from each of the tested radial ball bearing for rolling bearing units. The samples 1, 2 and 3 were mounted for LOM and SEM to analyse for damage as shown in Table 1.

\section{TEST RESULTS AND DISCUSSION}

The section presents the results that were obtained by using the methodology as presented in the previous section. The results are presented as samples 1,2 and 3. The SEM photographs of ball bearings retrieved from samples 1, 2 and 3 are as shown in Figure 5, Figure 6 and Figure 7 respectively. The Jeol JSM 6610 SEM had a magnification factor of 60 and a size scale of $200 \mu \mathrm{m}$.

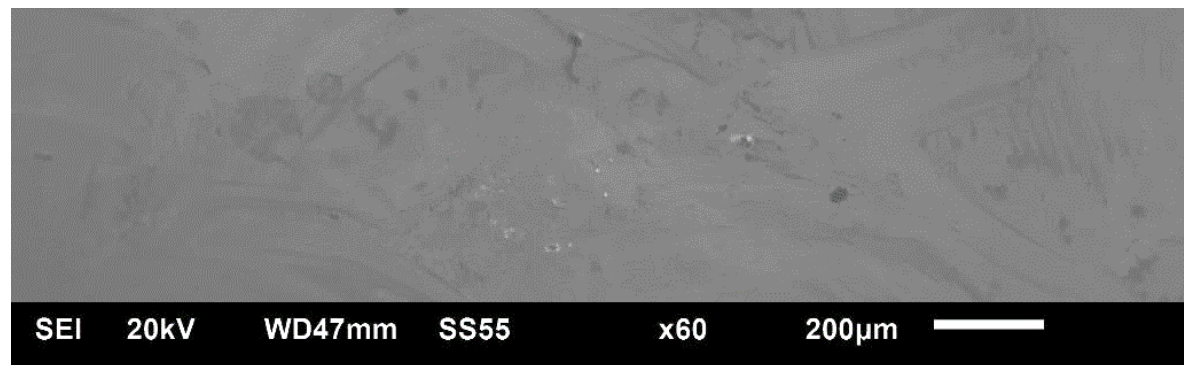

Figure 5. SEM photograph of a ball bearing: Sample 1 - Unused bearing. 


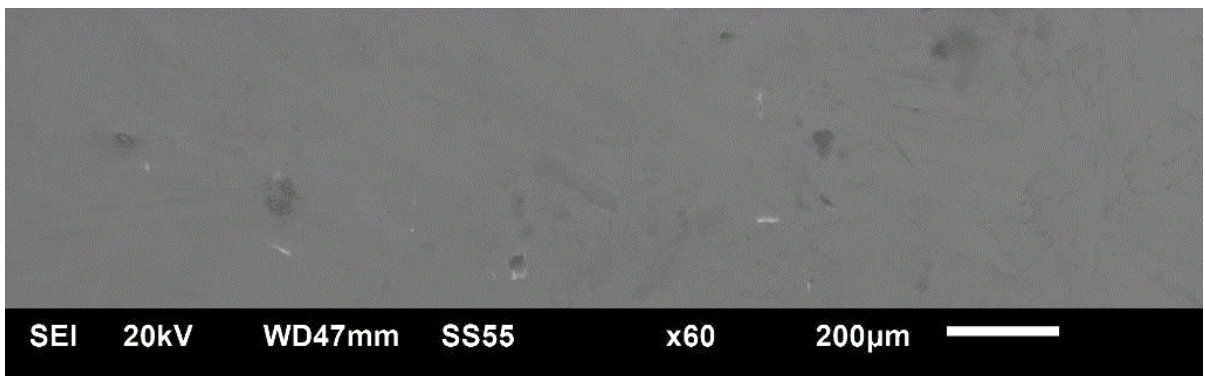

Figure 6. SEM photograph of a ball bearing: Sample 2 - Used with no ECD.

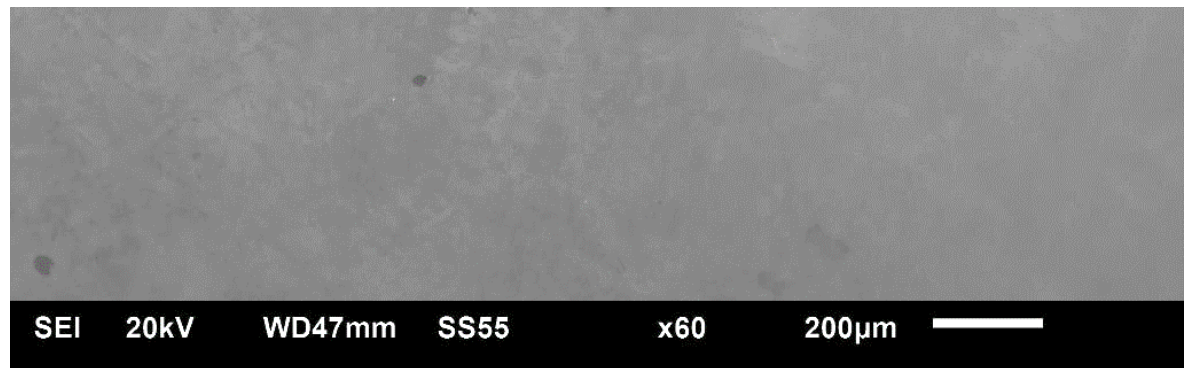

Figure 7. SEM photograph of a ball bearing: Sample 3 - Used with ECD.

Sample 1 (see Figure 5) shows the surface of an unused ball bearing which served as the control sample. Bearing manufacturers polishes rolling elements to an average surface roughness of $0.05 \mu \mathrm{m}$ (Jacobs, 2014). The irregular scratch marks on the surface could be due the unavoidable ball to ball collisions in the polishing process (Pattabhiraman et al., 2010). Sample 2 (see Figure 6) shows a polished surface of a ball bearing. During run in, a mild degree of polishing occurred between contacting asperities and were worn down that produced fine abrasive particles. The polishing results in a satisfactory contact between surfaces which is considered acceptable wear and tear ("Polishing - Bearing failure", n.d.). Sample 3 (see Figure 7) shows a dull surface appearance that is characterized by small craters of a few microns in diameter. Micro-cratering is a result of electric current passage in the bearing (SKF Group, 2006). The LOM photographs of the outer raceway of samples 1, 2 and 3 are as shown in Figure 8, Figure 9 and Figure 10 respectively. The Celestron 44302 LOM had a magnification factor of 3. 


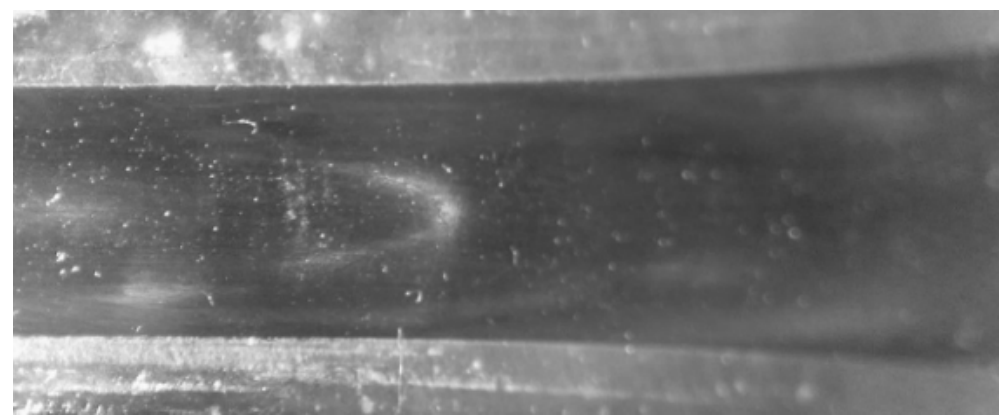

Figure 8. LOM photograph of the outer race: Sample 1 - Unused bearing.

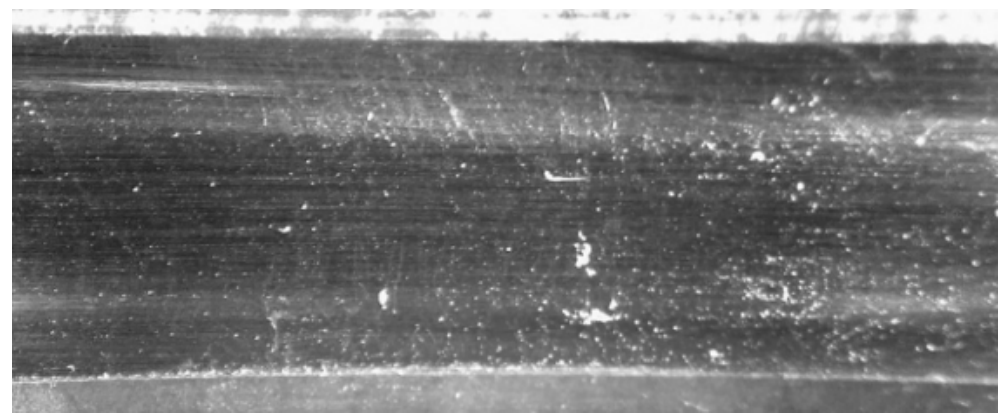

Figure 9. LOM photograph of the outer race: Sample 2 - Used with no ECD.

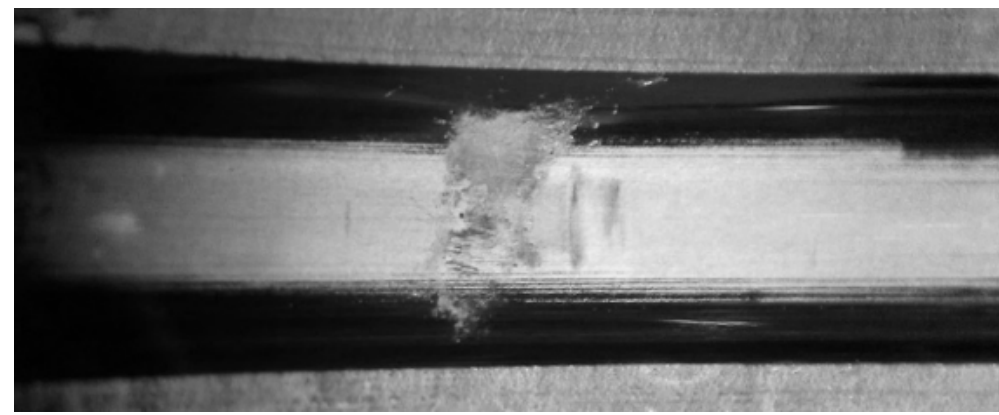

Figure 10. LOM photograph of the outer race: Sample 3 - Used with ECD.

Sample 1 (see Figure 8) shows the unused surface of an outer raceway which served as the control sample. The surface showed no observable damage. Sample 2 (see Figure 9) showed scratch marks on the raceway surface, parallel to the rolling direction. A higher magnification of the localized areas of samples 1 and 2 were sought with SEM (see Figure 11 and Figure 12). The Jeol JSM 6610 SEM had a magnification factor of 130 and a size scale of $100 \mu \mathrm{m}$. Similar to the results obtained from the ball bearing samples 1 and 2 (see Figure 5 and Figure 6), the raceway samples 1 and 2 had a mild degree of polishing that occurred between contacting asperities that worn down that produced fine abrasive 
particles. For abrasive wear to occur, the fine particles, or one of the contacting surfaces, needs to be substantially harder than the abraded surface. The abrasive wear process leads to a characteristic surface topography of long grooves running in the sliding direction (Jiménez \& Bermúdez, 2011). Sample 3 (see Figure 10) showed localised damage on the outer raceway surface (circle shown in Figure 10). The damage was observed to be adjacent to the anode terminal (see Figure 4 and Table 2). A higher magnification of the localized area of samples 3 was sought with SEM (see Figure 13).

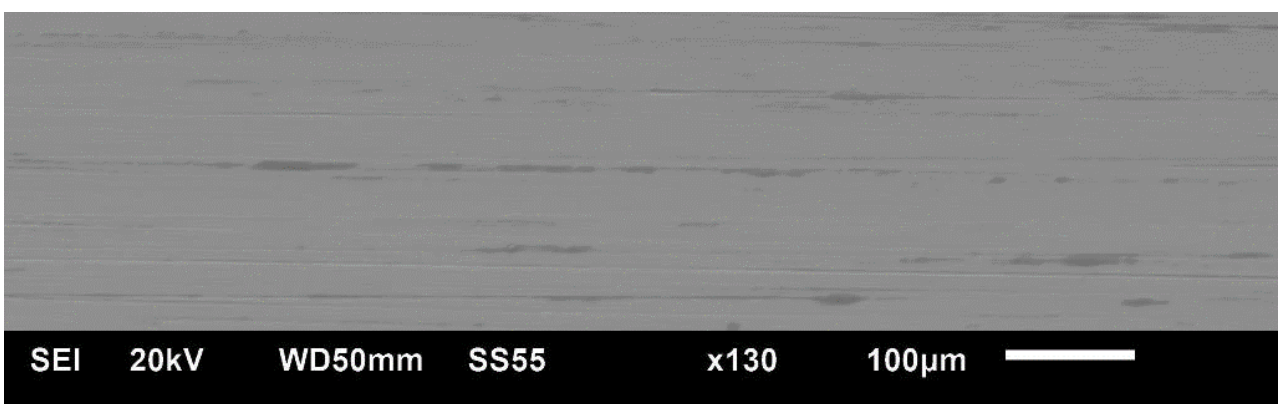

Figure 11. SEM photograph of the outer race: Sample 1 - Unused bearing.

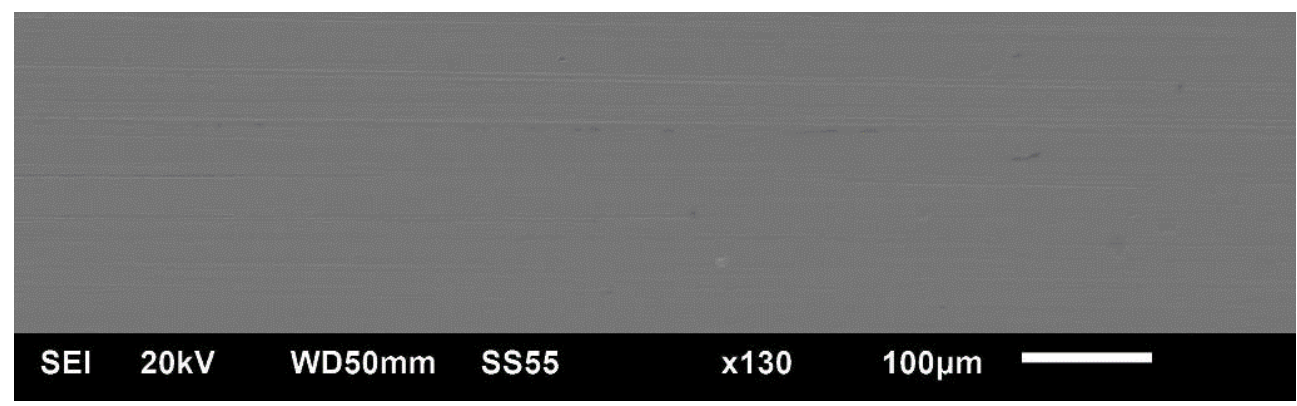

Figure 12. SEM photograph of the outer race: Sample 2 - Used with no ECD.

The SEM photograph of the outer raceway of sample 3 is as shown in Figure 13. The Jeol JSM 6610 SEM had a magnification factor of 11 and a size scale of $1 \mathrm{~mm}$. Sample 3 (see Figure 13) shows micro arching marks on the raceway surface leading towards the groove of the synthetic rubber seal and steel plate slinger (see Figure 3). The arcing marks are typical proof of electric current passage in the bearing (Liu, 2014). A higher magnification of the localized area of samples 3 (circle shown in Figure 13) was sought with SEM. The Jeol JSM 6610 SEM had a magnification factor of 35 and a size scale of $500 \mu \mathrm{m}$ was used as shown in Figure 14. 


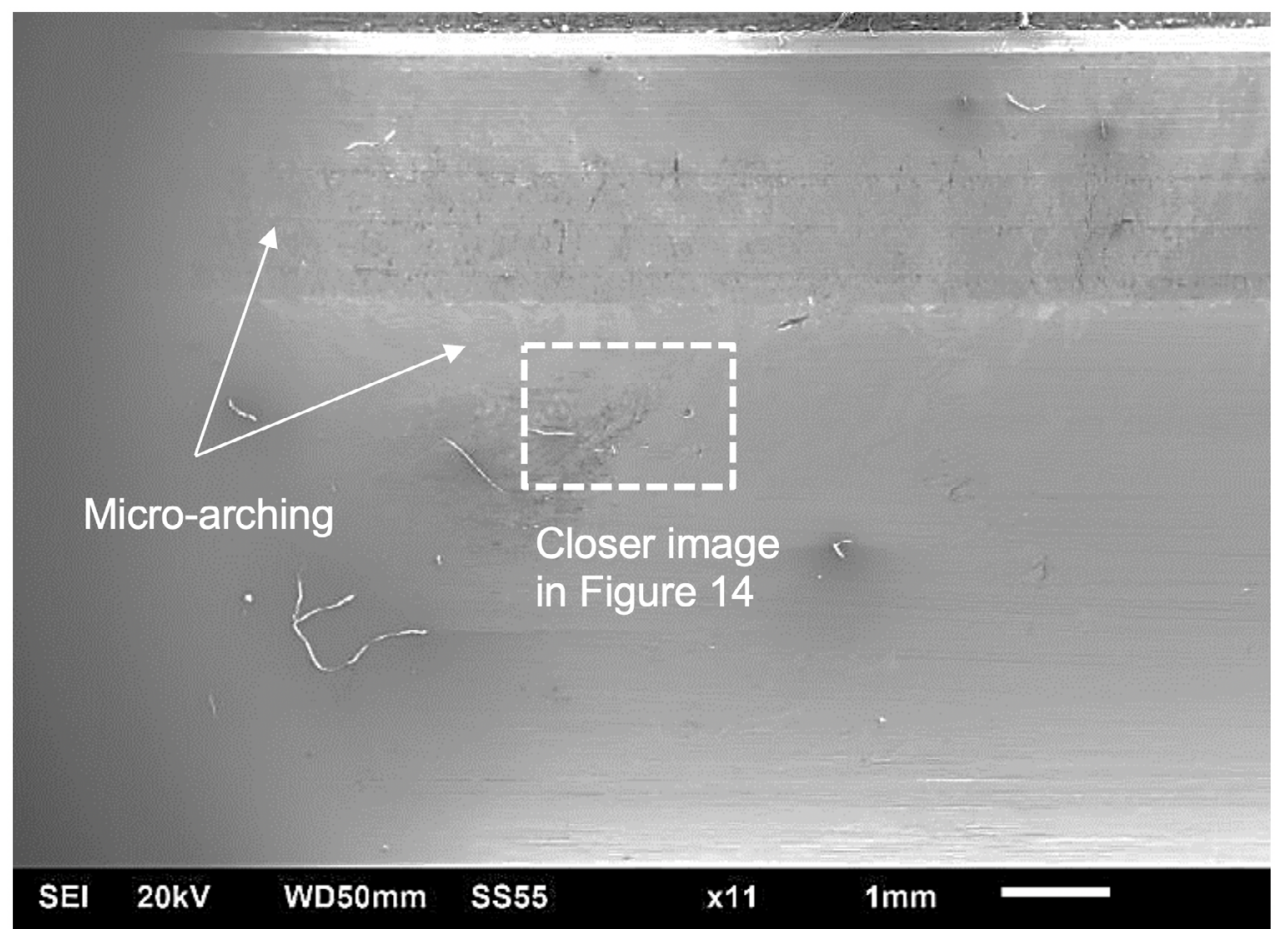

Figure 13. SEM photograph of the outer race: Sample 3 - Used with ECD.

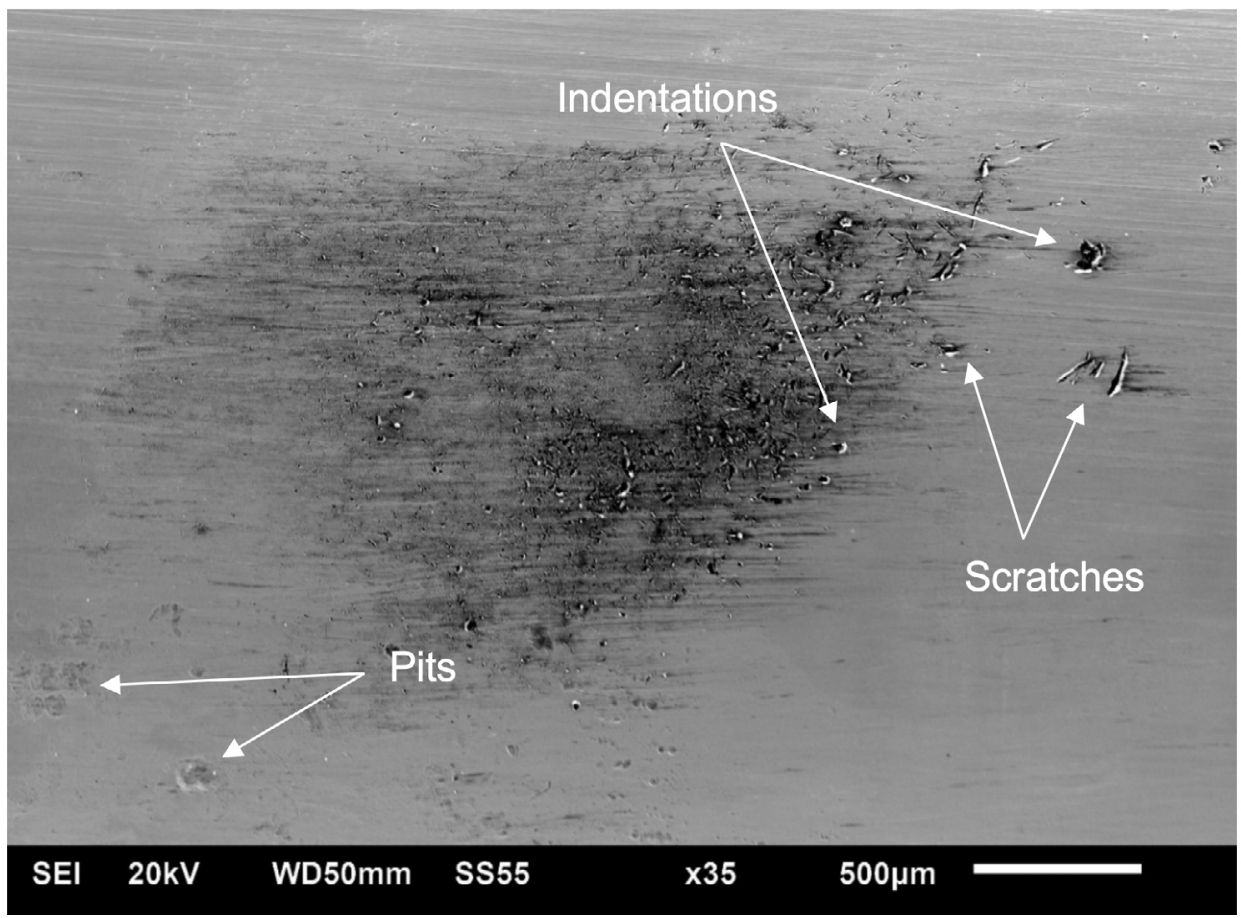

Figure 14. SEM photograph of the outer race: sample 3 - Used with ECD. 
Sample 3 (see Figure 14) shows many surface pits which were produced by electrical arching (Raadnui, 2012). A few deep scratches and indentations are observed on the raceway surface. This is due to the abrasive wear particles embedded in the raceway surface and ploughed away (Aditya, Amarnath, \& Kankar, 2014). Any rolling bearing has some degree of sliding due to the difference in the internal geometry and loading conditions of the bearing (Morales-Espejel, 2019).

\section{CONCLUSION}

The purpose of this paper was to present an innovative jig that may be used to expose mechanical bearings to ECD, in order to clarify its associated effects on the bearing that need to be understood before any mitigating techniques can be proposed. The ball bearing exposed to ECD showed a dull surface appearance that is characterized by small craters of a few microns in diameter. Micro-cratering is a result of electric current passage in the bearing. Micro-arching marks were observed on the outer raceway surface. The arcing marks are typical proof of electric current passage in the bearing. A few deep scratches and indentations are observed on the raceway surface. This is due to the abrasive wear particles embedded in the raceway surface and ploughed away due to the difference in the internal geometry and loading conditions of the bearing. The aspect of electrical pitting wear and debris found in the lubricating oil deserve further research from a tribological point of view. Some practical solutions to mitigate bearing currents has worked effectively for sinusoidal alternating currents. Some of the solutions are not as effective against the fast switching Pulse Width Modulation (PWM) inverter technology that causes high frequency non-sinusoidal bearing current. The foremost limitation of this article is that neither the voltage, nor the current values of ECD are known. A recommendation is made to conduct qualitative research with the innovative jig to test the impact of ECD on bearings from other suppliers. The obtained primary data will warrant similarities or differences present in used ball bearings exposed to ECD. 


\section{REFERENCES}

Aditya, S., Amarnath, M., \& Kankar, P. K. (2014). Failure Analysis of a GreaseLubricated Cylindrical Roller Bearing. Procedia Technology, 14, 59-66. https://doi. org/10.1016/j.protcy.2014.08.009

Bergström,J. (2015). Chapter 2 - Experimental Characterization Techniques. In Mechanics of Solid Polymers - Theory and Computational Modeling. Elsevier, 19-114.

Bhadeshia, H. K. D. H. (2012). Steels for bearings. Progress in Materials Science, 57(2), 268435. https://doi.org/10.1016/j.pmatsci.2011.06.002

Bhadeshia, H. K. D. H. (n.d.). Mechanical Bearings. University of Cambridge. https:// www.phase-trans.msm.cam.ac.uk/2010/types/index.html

Bizwit Research \& Consulting LLP. (2019, May 15). Global Bearings Market Size study, by product (Roller Bearings, Ball Bearings and others) Application (Automotive, Agriculture, Electrical, Mining \& Construction, Railway \& Aerospace, Automotive Aftermarket and Others) and Regional Forecasts 2018-2025. https://www.wiseguyreports.com/reports/4041840-globalbearings-market-size-study-by-product-roller\#

Chiou, Y.-G., Lee, R.-T., \& Lin, S.-M. (2009). Formation mechanism of electrical damage on sliding lubricated contacts for steel pair under DG electric field. Wear, 266, 110-118. https://doi.org/10.1016/j.wear.2008.06.001

ETK Bearing Company. (n.d.). Bearing Units Introduction \& Selection. http://www. etkbearing.com/about/?72.html

Gianfrancesco, A. D. (2017). Chapter 8 - Technologies for chemical analyses, microstructural and inspection investigation. In Materials for Ultra-Supercritical and Advanced Ultra-Supercritical Power Plants. Elsevier, 197-245. https://doi.org/10.1016/ B978-0-08-100552-1.00008-7

Ingham, J. P. (2013). Chapter 1 - Introduction. In Geomaterials Under the Microscope. Elsevier, $7-20$. 
Jacobs, W. (2014). Experimental analysis of the dynamic characteristics and lubricant film of a ball bearing under combined static and dynamic load. KU Leuven - Faculty of Engineering Science.

Jacobs, W., Van Hooreweder, B., Boonen, R., Sas, P., \& Moens, D. (2016). The influence of external dynamic loads on the lifetime of rolling element bearings: Experimental analysis of the lubricant film and surface wear. Mechanical Systems and Signal Processing, 74(1), 144-164. https://doi.org/10.1016/j.ymssp.2015.04.033

Jiménez, A.-E., \& Bermúdez, M.-D. (2011). Chapter 2 - Friction and wear. In Tribology for Engineers A Practical Guide. Woodhead Publishing Limited, 33-63.

Liu, W. (2014). The prevalent motor bearing premature failures due to the high frequency electric current passage. Engineering Failure Analysis, 45, 118-127. https://doi. org/10.1016/j.engfailanal.2014.06.021

Massi, F., Rocchi, J., Gulla, A., \& Berthier, Y. (2010). Coupling system dynamics and contact behaviour: Modelling bearings subjected to environmental induced vibrations and 'false brinelling' degradation. Mechanical Systems and Signal Processing, 24(4), 1068-1080. https://doi.org/10.1016/j.ymssp.2009.09.004

McIntosh, A., \& Pontius, J. (2017). Chapter 1 - Tools and Skills. In Science and the Global Environment. Case Studies Integrating Science Global Environment. Elsevier, 514.

Morales-Espejel, G. E. (2019, June 28). Wear and surface fatigue in rolling bearings. http:// evolution.skf.com/wear-and-surface-fatigue-in-rolling-bearings/

NTN Corporation. (2015). Ball and Roller Bearings. https://www.ntnglobal.com/en/ products/catalog/pdf/2202E_all.pdf

NTN Gorporation. (2018). Bearing Units. https://www.ntnglobal.com/en/products/ catalog/pdf/2400E_all.pdf 
Pattabhiraman, S., Levesque, G., Kim, N. H., \& Arakere, N. K. (2010). Uncertainty analysis for rolling contact fatigue failure probability of silicon nitride ball bearings. International Journal of Solids and Structures, 47(18-19), 2543-2553. https://doi. org/10.1016/j.ijsolstr.2010.05.018

Polishing - Bearing failure. (n.d.). https://onyxinsight.com/wind-turbine-failuresencyclopedia/bearing-failures/polishing/

Raadnui, S. (2012). Between "ferrogram" and "filtergram" makers is the multiple centrifiltergram maker: a new technique for solid debris separation. Fournal of Physics: Conference Series, 364, 1-7. https://iopscience.iop.org/ article/10.1088/1742-6596/364/1/012087

Robinson, N. (n.d.). Monitoring oil degradation with infrared spectroscopy. Wearcheck Division of Set Point Technology. Technical Bulletin, (18). http://www.wearcheck. com/virtual_directories/Literature/Techdoc/WZA018.pdf

Scimeca, M., Bischetti, S., Lamsira, H. K., Bonfiglio, R., \& Bonanno, E. (2018). Energy Dispersive X-ray (EDX) microanalysis: A powerful tool in biomedical research and diagnosis. European fournal of Histochemistry, 62(1), 1-10.

SKF explorer spherical roller thrust bearings boost design options. (2003, May 29). http://evolution.skf.com/skf-explorer-spherical-roller-thrust-bearings-boost-designoptions

SKF Group. (2006). Electrically insulated bearings from SKF. https://www.skf.com/binary/ tcm:12-295325/0901d1968008da41-6160-EN-Motor-Insocoat-hybrid_tcm_12295325.pdf

SKF Group. (2010). SKF spherical roller thrust bearings. For long lasting performance. https:// www.skf.com/binary/tcm:12-121034/0901d1968027f7c9-06104_1-EN_tcm_12121034.pdf

SKF Group. (2012a). Bearing in centrifugal pumps. Application handbook. https:/ /www.skf.com/ binary/26-154513/100-955-Bearings-in-centrifugal-pumps.pdf 
SKF Group. (2012b). Super-precision angular contact ball bearings: High-speed, B design, sealed as standard $S 719$.. B (HB .. /S) and $S 70$.. B (HX .. /S) series. https://www.skf.com/ binary/30-75457/0901d196801b304f-Super-precision-angular-contact-ballbearings-High-speed-B-design-sealed---06939_5-EN.pdf

SKF Group. (2014). SKF self-aligning ball bearings for the textile industry. https:/ / www.skf.com/ binary/21-161175/Self-aligning-ball-bearings-for-textile-industry.pdf

SKF Group. (2018). Self-aligning ball bearings. http://www.bearing.net.au/wp-content/ uploads/2018/02/6000_EN_03_SABB.compressed.pdf

SKF Group. (n.d.a). Bearing arrangements. https://www.skf.com/africa/en/products/ bearings-units-housings/super-precision-bearings/angular-contact-thrust-ballbearings-for-screw-drives/bearingarrangementdesign/bearing_arrangements/ index.html

SKF Group. (n.d.b). Self-aligning ball bearings. https://www.skf.com/africa/en/products/ bearings-units-housings/ball-bearings/self-aligning-ball-bearings/index.html

SKF Group. (n.d.c). Needle roller bearings. https://www.skf.com/africa/en/products/ bearings-units-housings/roller-bearings/needle-roller-bearings/index.html

SKF Group. (n.d.d). U-joints. https://www.skf.com/ca/en/products/vehicle-aftermarket/ automotive/drivetrain/u-joints/index.html

SKF Group. (n.d.e). Insert bearings (Y-bearings). https://www.skf.com/uk/products/bearingsunits-housings/ball-bearings/insert-bearings/index.html

Upadhyay, R. K., Kumaraswamidhas, L. A., \& Azam, S. (2013). Rolling element bearing failure analysis: A case study. Case Studies in Engineering Failure Analysis, 1(1), 15-17. https://doi.org/10.1016/j.csefa.2012.11.003 